\title{
11. Artisanal and Small-Scale Mining: Gender and Sustainable Livelihoods in Mongolia
}

\author{
Bolormaa Purevjav
}

\section{Introduction}

The practice of artisanal and small-scale mining (ASM) has grown considerably in Mongolia since the country transitioned from a socialist state to a marketbased economy with a heavy reliance on mining and resource extraction. Calls to ban ASM due to lack of regulation and environmental and health concerns have failed to gain support because of the large numbers of the rural poor that have adopted ASM as a livelihood strategy to supplement diminishing incomes from agriculture. Instead, the Mongolian government has sought to regulate and reform the sector by offering skills training and increasing the capacity of ASM collectives. Women are actively involved in ASM in large numbers in Mongolia, as they are in many other parts of the world, due to their exclusion from employment in large-scale mining and deepening rural poverty. Despite policy commitments to gender equality, women in Mongolia struggle to find equal employment and women are attracted to ASM due to the absence of barriers that characterise employment in the formal sector. Mongolia's adoption of the Millenium Development Goal 3 (MDG 3), namely to 'promote gender equality and empower women', has resulted in the acknowledgement and incorporation of gender in the ASM reform program. This chapter describes the gendered practice of ASM in Mongolia and how the government in partnership with the Swiss Agency for Development and Cooperation (SDC) is attempting to reform the ASM sector in a gender-sensitive way through the Sustainable Artisanal Mining Project.

\section{Mining and Economic Development}

Mongolia is one of the least populated countries in the world. The territory of Mongolia measures 1564116 square kilometers - the nineteenth largest country in the world - yet has a population of only 2.6 million people. It is a landlocked country between Russia and China, located on the plateau of Central Asia; far from sea ports and transport networks. Mongolia's geography features high 
mountains in the west, wide open steppes in the east, the Great Gobi Desert in the south and the Taiga Forest in the north. Its climate is continental; long winters with frequent snow fall, springs with persistent winds, hot and very dry summers, and a short agricultural season. In particular, this geography and climate significantly affects the living conditions of rural people in Mongolia and presents a challenge to livestock husbandry and agriculture. Unaffected by these harsh climactic conditions, Mongolia's mineral wealth has become a key part of its economic development in the past two decades.

From 1921 to 1990 Mongolia was a socialist country. The socialist state system provided universal access to social services and all people were employed in state-owned cooperatives and institutions. In general, it offered considerable security and a decent standard of living. However, the socialist system ignored the desires and aspirations of individuals, curbed people's political freedom and was based on a centralised, authoritarian control.

In the early 1990s, when the socialist system became incapable of governing the country effectively, radical political and economic changes were introduced to re-define the country's economic development. Since then, Mongolia has undergone dramatic changes: foreign relations have expanded; rural-urban socio-economic disparities have deepened, significantly contributing to internal and international migration; a new constitution was approved and the legislative, executive and judicial powers are now distributed amongst the presidency, parliament, government and the supreme court. Today Mongolia is a democratic country that respects human rights and freedoms and has adopted a market-based economy, based on foreign investment, the expansion of the private sector and multiple forms of individual property ownership.

During the initial years of transition from a socialist to a market-based economy (from 1990-1993), Mongolia's gross domestic product (GDP) decreased by 20 per cent and many industries collapsed. The economic downturn resulted in high unemployment and a dramatic increase in poverty. From 1994-2002 Mongolia experienced rapid economic development and GDP grew by two per cent per capita on average. In 2003 GDP grew by 5.6 per cent, in 2004 by 10.6 per cent, in 2005 by 7.1 and in 2006 by 8.4 per cent. The acceleration of economic growth was largely based on the expansion of the agricultural, mining and service sectors. The formal, large-scale mining sector has been the largest contributor to Mongolia's economic growth - growing around ten per cent every year since 1991. In 2007, the mining and extractive industries constituted 27.5 per cent of GDP, agriculture, hunting and forestry constituted 20.6 per cent, wholesale and retail trade 14.2 per cent and the transportation and storage sector 10 per cent (NSOM 2007). 
Unfortunately Mongolia's economic growth has not benefitted all segments of society. Despite consistent GDP growth over the past two decades, few new jobs have been created and poverty and unemployment remain high. According to recent research, 36 per cent of the population still lives in poverty. Rural areas remain the poorest due to lack of employment opportunities. People living in rural areas have responded to the challenges brought about by the structural adjustment of the economy by working in the informal sector-in particular, artisanal and small-scale mining in increasing numbers (UNDP Mongolia 2008).

\section{Development and Growth of ASM}

Artisanal and small-scale mining (ASM) developed in Mongolia in the early 1990s in response to several factors; diminishing employment and livelihood opportunities in rural areas being the primary cause. Mongolia experienced a series of particularly severe winters with heavy snowfall between 1997 and 2002, which exacerbated levels of poverty and hardship for those dependent on agriculture and animal husbandry. An alarming rate of depletion of livestock through uncontrolled use of natural resources by powerful elites has also threatened rural livelihoods in recent years. These factors, combined with the relative geological wealth of Mongolia's rural areas and the introduction of the Liberal Mining Law in 1997, which opened up 45 per cent of the country to mineral exploration (including areas that had been used for herding and breeding livestock) and greatly expanded foreign-owned mining activity, saw many rural people turn to ASM as an alternative livelihood (see Table 11-1).

Table 11-1: Number of artisanal miners: 2000-2008.

\begin{tabular}{cc}
\hline Year & Number of artisanal miners \\
\hline 2000 & 20000 \\
2003 & 100000 \\
2006 & 96000 \\
2007 & 67000 \\
2008 & 54000 \\
\hline
\end{tabular}

Note: the decrease in artisanal miners in 2007 and 2008 was due to confiscation of ASM mills by the government and prohibition of milling operations using mercury. Source: MRPAM (2007).

ASM refers to mining by individuals, groups and families. It is an activity of simplified mineral extraction of primary and secondary deposits. ASM activities are typically highly mobile and labour-intensive - the generally small deposits are usually exhausted after only a few years and tools and extraction methods are rudimentary and manually-operated. In contrast to large-scale mining, ASM 
has only two phases: extraction and processing. Most significantly however, is that ASM creates far more jobs in rural areas than large-scale mining and thus holds greater potential for reducing poverty.

ASM has developed and expanded informally in Mongolia over the past 15 years, until February 2008, when the Government of Mongolia approved the temporary regulation of ASM. This temporary regulation has provided artisanal miners with rights to mine but with limited land rights. Prior to this temporary regulation, ASM was regarded as highly disorganised and environmentally damaging by the central government, as well as large mining companies and environmental agencies, who lobbied to prohibit it.

As with other informal livelihood activities, ASM presents numerous human and environmental hazards: health problems due to harsh weather conditions and poor occupational safety; limited access to social services and assistance; lack of training in the knowledge and skills required to undertake mining activities; conflict with others; illegal digging in the licensed areas of large mining companies and pasture degradation. Unsecured mine sites pose dangers to children and animals, unsafe use of toxic chemicals such as mercury has led to disease and ASM has increased prostitution and the spread of sexually transmitted diseases (STDs) and HIV/AIDS, as well as the use of child labour.

While all of these hazards present regulation and legal challenges for governments, in Mongolia artisanal miners currently comprise 20 per cent of the employed or 'economically active' population - three times the number employed in the large-scale mining sector (ADB Mongolia 2008). Due to the high number of people engaged in ASM and the relatively good income levels it generates, the government had little choice but to take a positive step towards recognition of ASM as a source of 'formal' employment by issuing the temporary regulation.

\section{ASM and Sustainable Livelihoods}

Unofficial statistics suggest that ASM currently provides employment for approximately 100000 people and produces an estimated 5-10 tonnes of gold per annum, generating an estimated annual production revenue of between US $\$ 60-120$ million. ASM is practiced at over 100 sites across 19 provinces in Mongolia. The majority of artisanal miners engage in hard and placer gold mining (80-90 per cent), with the rest engaged in fluorspar and coal mining. As these figures demonstrate, ASM provides important development opportunities from both a macro-economic and socio-economic perspective. ASM is critically important for local communities as it provides vital temporary and full time work, despite its negative health and environmental implications. As artisanal 
miners use simple tools and equipment which do not require specialised skills, the overall entry cost to ASM is relatively low. Thus it provides an opportunity for the very poor to earn an income.

Given its current rate of expansion and levels of participation, ASM operations have reached the benchmark of a sub-sector in Mongolia. Rather than ban ASM, the state provides support in terms of the establishment of a legal framework in which ASM can safely operate although organisational and institutional capacity building have been called for in order to protect livelihoods. Despite the temporary regulation of ASM by the Mongolian government, obstacles remain to its inclusion in the mainstream economy. It is still not possible to sell ASM-derived gold to the Bank of Mongolia and currently all gold produced by artisanal miners is smuggled by tradesmen over the green border into China. The economic potential of ASM is further constrained by poor work practices and standards of processing. The absence of a regulatory framework and secure rights for artisanal miners have exacerbated existing problems and conflicts both within the sector and between ASM and the formal mining sector.

In order for local communities to maximise the benefits of ASM, the government needs to integrate ASM into rural development strategies and support a range of reforms. These include establishing a regulatory framework and the introduction of workplace training and standards of practice, such as the safe use of toxic chemicals, disposal of toxic waste and occupational health and safety. To improve the extraction of deposits, promotion of more efficient ASM tools and processes is needed. This will also bring environmental benefits and help to make ASM a more sustainable industry. Lastly, a regulatory framework with a clear definition of the rights and responsibilities of artisanal miners would contribute to local development and ensure that artisanal miners can become valued members of society.

Because the challenge of sustainable development is to achieve a steady economic growth rate and address social needs while not depleting natural resources, the development of ASM requires a holistic approach that considers the environmental, economic and social challenges together (see Figure 11-1). The development of an ASM policy framework for Mongolia also requires strong partnerships and cooperation between all relevant stakeholders, including international organisations, to tackle the complex issues involved and enable ASM to act as a 'motor' for sustainable rural development. 


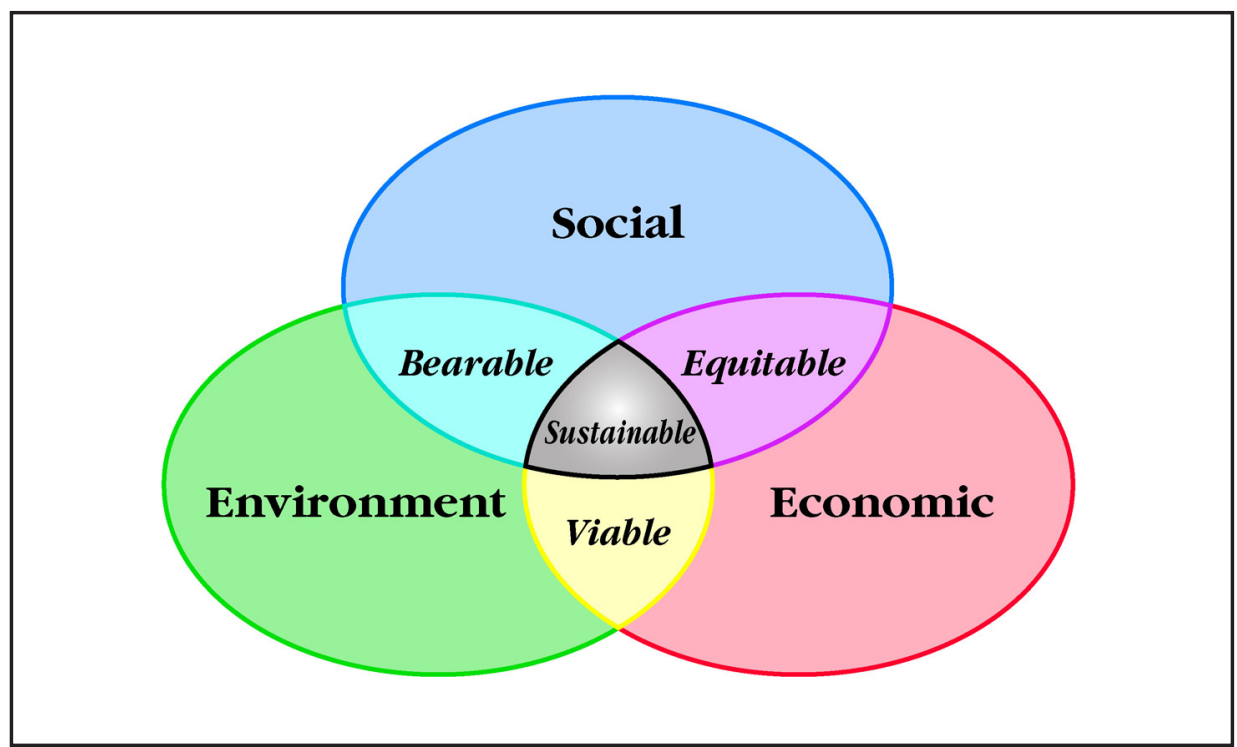

Figure 11-1: The heart of sustainable development: addressing economic, environmental and social aspects equally.

At all levels of the Mongolian government there is a belief that large-scale mining is the best option for economic development. The argument is that because it is easier to control, it contributes tax revenue and therefore has stronger national economic benefits. However, international experience shows that ASM can be a motor for rural development. Examining ASM purely from a social perspective, we find it creates much-needed work and is a major source of income in rural areas. Although there are environmental impacts and risks, artisanal and smallscale miners typically mine the smallest deposits, and rework dumps and tailings. From a macroeconomic perspective, ASM offers further benefits in terms of multiplier effects: it mobilises natural resources, generates revenue, activates trade and contributes to local development through money circulation, investment activities and demand for product and services.

If effectively regulated, ASM could also contribute to the achievement of Mongolia's Millennium Development Goals (MDGs). Specifically it could contribute to achievement of the following goals:

- Reduce by half the proportion of people living on less then one dollar a day.

- Promote gender equality and empower women.

- Combat HIV/AIDS and other diseases.

- Ensure environmental sustainability.

- Develop global partnerships for development. 
Despite these benefits, both real and potential, ASM entails numerous costs. From a geological perspective, the costs include exploitation of a nonrenewable resource; losses through unsustainable exploitation of the highest grade minerals; low recovery due to mining methods and the impacts of mineral transportation. The environmental costs include deterioration and destruction of surrounding land, soil, ground and surface water, air, flora and fauna, energy sources and ecosystems. In terms of social costs, ASM entails the aforementioned low occupational safety standards and high health risks as well as poor living conditions, complex economic dependencies, lack of social security, alcoholism, crime, prostitution, child labour, violation of local community rights and conflict (UNFPA 2007).

\section{Gender and Development}

The state of gender relations and equality in Mongolia offers a contradictory picture. On the one hand, Mongolia has relatively high Gender Development Indicator (GDI) figures, has embraced MDG 3 and has a number of progressive gender equity policies in place. Women's mortality rate has fallen in recent years (although rates in rural areas remain high) and women's level of educational attainment is often higher than that of men (ADB Mongolia 2008). Despite these gains, in practice women continue to receive less pay than men, have fewer employment opportunities and are found in less managerial positions across professions and sectors. Despite recent strong economic growth, inequalities are increasing, particularly between urban and rural areas and women in particular are entering the informal sector in greater numbers (including ASM), with fewer protections and lower wages. Gender relations in Mongolia are also being transformed by high rates of male suicide and early mortality, alcoholism, gender-based violence and unemployment (ibid.).

In terms of gender equality legislation, the Mongolian Constitution, Labor Law, Family Law, Civil Code and Criminal Code contain provisions to promote gender equality. The Constitution provides equal rights for women and men in political, economic, social, cultural and family life, and prohibits all kind of discrimination based on sex. The 1999 Labor Law also prohibits gender-based discrimination in employment and contains a section addressing maternity rights. The approval of a Domestic Violence Law in 2004 represented a significant step in strengthening women's rights and efforts to reduce violence against women. The amendment to the Criminal Code in 2008, which included a full definition of trafficking according to international standards, is another milestone in the area of gender equality and protection of women's rights. 
In 2005 the Mongolian Parliament passed a resolution on MDG 3 in order to improve the social, professional and cultural status of Mongolian women and promote their participation in broader development policies and programs. The MDG-based long-term National Development Strategy (NDS) was adopted by Parliament in February 2008 (NDS 2008). The NDS is the main policy document that guides and coordinates all national policies, programs, and laws with sector strategies aligned to NDS mandates. The gender equality policy for NDS is to 'ensure human rights-based gender development through universal gender education and provision of gender equality in the labor market...', and contains provisions to increase the number of female candidates for parliamentary elections.

The key government mechanism for gender equality, the National Committee on Gender Equality (NCGE) was established in 2005 and is chaired by the Prime Minister. The NCGE has 33 members with representatives from government, the private sector, and NGO/civil society groups. The members are divided into five working groups to oversee thematic priorities, which include legislation; implementation of Committee on the Elimination of Discrimination against Women (CEDAW); gender research and monitoring; governance; and public relations. However, in practice most of the representatives have little knowledge of gender equality issues and lack a clear commitment to implement the NCGE.

Some of these legislative changes and policy measures are clearly having a positive affect on gender relations in Mongolia, although the statistics offer conflicting evidence. The Human Development Report of 2007 demonstrates that the Gender-Related Development Index (GDI) in Mongolia has risen in recent years, from a GDI of 0.693 in 2004 to 0.719 in 2006. However, the gender empowerment measure (GEM) worsened from 0.448 in 2002 to 0.422 in 2007, and is lower than its gender development index (GDI) value of 0.719 for 2007 (UNDP Mongolia 2008), evidencing inequality in economic and political opportunities.

Just as Mongolia's progressive gender policy framework obscures disparities in terms of income and labour market opportunities between men and women, Mongolia's increasing GDP has not decreased rates of poverty and inequality despite high literacy and school enrollment rates (see Table 11-2). A recent Country Gender Assessment provided evidence that the rapid economic growth in Mongolia over the last four to five years has not translated into a secure future for many men and women and that inequality based on income, gender and social exclusion is increasing. The poverty rate remains high, particularly in rural areas (37.9 per cent) compared to urban rates of poverty (27 per cent). Female-headed households continue to be poorer (43.8 per cent) compared to male-headed households (34.8 per cent). In rural areas, herder households are amongst the poorest, closely followed by female-headed households (ADB Mongolia 2008). 
Table 11-2: Mongolian Gender Indicators: 2006.

\begin{tabular}{lrr}
\multicolumn{1}{c}{ Gender Indicators } & Male & Female \\
\hline Life expectancy index (\%) & 62.6 & 69.3 \\
Adult literacy rate (\%) & - & 97.5 \\
Combined primary, secondary and tertiary gross enrollment ratio (\%) & 75.5 & 83.2 \\
GDP per capita (PPP) & 3.1 & 2.6 \\
\hline
\end{tabular}

Source: UNDP Mongolia (2008).

According to the Mongolian Office of National Statistics, in 2006 women made up over 50 per cent of the economically active population and 51.6 per cent of the employed workforce. Women represent a large proportion of clerks, service workers, professionals and technicians. The high female labor force participation vis-à-vis men reflects in part a reduction in the male working age population due to rising levels of male disability caused by working in high risk environments (chiefly the construction and mining sectors) where low occupational safety is in place, and high levels of mortality due to alcoholism and high health risk behavior. ${ }^{1}$

The high level of female workforce participation is not enough, however, to guarantee gender equality and the gender pay gap is widening. This is particularly evident in the education sector, where women make up the majority of employees but receive 87.6 per cent of average male salaries. Men in managerial positions across all sectors receive 22.8 per cent more in terms of salaries than women in similar positions. Women's pensions are also lower than men's and are a contributing factor to the relatively higher rates of female poverty.

The double work burden, care obligations and inadequate access to credit are the main disadvantages and obstacles women face in terms of accessing opportunities and equal pay within the labour market. Market reforms and cut backs on social welfare and child care have forced many women in Mongolia to take up low paying jobs in the informal sector, where the benefits of flexibility are traded off against wages and conditions. Child labour is also on the rise, particularly amongst those from poor, female-headed households. The ASM sector is one such sector witnessing an increase in both female and child labour (MEK Co. Ltd et al. 2005; MRPAM 2005).

\footnotetext{
1 Mongolia has witnessed an extraordinary increase in male mortality in the 20-34 age bracket, currently more than three times that of women in the same age bracket (NSOM 2007).
} 


\section{Gender and Employment: Formal and Informal Mining}

According to the 2008 Mongolian country gender assessment (ADB Mongolia 2008), women employed in the formal mining sector receive on average 80.9 per cent of male salaries. In the informal sector, women receive considerably less - just 50 per cent of men's wages. However, women's ability to access work in the formal mining sector is considerably more difficult than it is within the ASM sector. Mining company job advertisements openly express a preference for male employees due to the general harshness of conditions, which are not thought to be suitable for women.

While jobs in mining and construction are high paying, the lack of enforcement of labour standards and safety measures has resulted in high levels of workplace deaths and accidents amongst employees, increasing the ranks of men in the long-term unemployed due to disability. This has increased the number of female-headed households and women's economic burden, compelling both women and children to accept exploitative and high risk forms of employment, such as ASM and semi-voluntary prostitution. Increased domestic and genderbased violence in Mongolia has also been associated with men's loss of economic power as well alarming rates of alcoholism.

In contrast to the large-scale mining sector, both men and women work in ASM in Mongolia - primarily from poor, rural areas. A socio-economic survey of artisanal miners in gold mining conducted by UNFPA (2007) found that overall 65 per cent of artisanal miners are men and 35 per cent are women. Within the sector men outnumber women by 71 per cent to 29 per cent in hard rock gold mining, while in placer gold mining men represent 61 per cent of miners and women 39 per cent. Placer gold mining is more accessible for women, as it has lower initial costs than hard rock mining and does not require working in groups of 4-5 people - placer gold miners can work alone or in smaller groups of two-three people.

The majority of artisanal miners (66.7 per cent) are involved in alluvial mining, with the remaining 33.3 per cent involved in hard rock mining. The age of informal miners ranges from 15-55, divided evenly with 50 per cent of the workforce below and 50 per cent above 33 years of age. Single, uneducated men make up a large proportion of those in the 20-25 age bracket. The majority of women (80.6 per cent) engaged in ASM are in the 35-39 age bracket. Of these women, 74.2 per cent have families. Men predominate in placer gold mining (61.3 per cent as compared with 38.7 per cent women) and are also engaged in hard rock mining in greater numbers as compared to women-71.4 per cent as opposed to 28.6 per cent. In terms of educational attainment, 34.6 per cent of 
artisanal miners have completed secondary education. More women than men have a complete secondary education - 39 per cent for women as compared with 32.2 per cent for men - suggesting that for some women, working in ASM reflects difficulties in accessing skilled employment opportunities in the formal sector.

Women and men do equal work across a wide range of ASM activities, including ore sack transportation, gold separation using water or blowing, digging, lifting ore sacks from up to 20 metre deep holes, working inside deep holes and vertical tunnels, milling, crushing and sluicing. Accordingly, both men's and women's health are equally affected by the harsh weather conditions and low occupational safety of ASM work. Although high numbers of women are involved in mining and carry out the same tasks as men, they are still also largely responsible for reproductive work in the home, including food preparation, fetching water, gathering wood fuel, and caring for children, the elderly and sick. Women are also primarily responsible for running small shops, all of which creates a significant paid and unpaid work burden for women engaged in ASM.

The main gender issues in ASM in Mongolia are thus similar to those faced by women in other sectors - namely women's double work burden and lower levels of pay for the same work. Child labour is a problem for both genders, as is poor working and harsh weather conditions and the resultant health impacts, however younger children and girls are paid in kind (mainly food) while older male children are paid in cash, revealing that gender disparities in pay begin early on in life. For all age groups, wages are lower for girls than for boys and furthermore, in the case of gold and fluorspar mining, the boys represent over 80 per cent of the total child workforce (MEK Co. Ltd et al. 2005). Child labour in ASM can be seen as a gendered issue in so far as it reflects the increasing rates of poor, female headed-households and male bread-winner disability and mortality.

Given the high numbers of women engaged in ASM, a gender mainstreaming approach to the reform and regulation of the sector is warranted, in order to affectively address gender issues. At a government level, a range of gendersensitive health programs and policies are needed for the sector. This should involve men and women participating equally in capacity building training programs, ASM community associations and actions, support to develop gender sensitive ASM institutions, programs and training manuals. It also means ensuring that men and women have equal rights and access in terms of the opportunities provided by improvements to ASM technology, the availability of credit and health services in mining areas or nearby mining areas. 


\section{MRPAM and SDC: Sustainable Artisanal Mining Project}

The Mineral Resources and Petroleum Authority of Mongolia (MRPAM) recently developed a sub-program for the development of ASM in Mongolia which will run until 2015. The sub-program was approved by the same Government Resolution which approved the temporary regulation of ASM. The regulation has just been implemented, but it is hoped that feedback from local government authorities and artisanal miners will be reflected in policy documents as well as future improvements and modifications to the resolutions. The greatest achievement of these resolutions is that they recognise ASM as a legitimate economic activity and oblige government agencies to coordinate their activities.

To help deliver the program of reform to ASM, MRPAM has partnered with the Swiss Agency for Development and Cooperation (SDC) to manage and deliver the Sustainable Artisanal Mining Project (see Grayson et al. 2004; Janzen et al. 2007; SDC 2010). Project staff have been working with both the government and ASM communities to develop an appropriate legal framework, identify strategies to build the capacity of ASM communities and deliver education and training. The main goal of the project is to contribute to the development of responsible artisanal mining in Mongolia, improve the well being of artisanal miners (men and women) in a cost effective and sustainable manner and thus contribute to rural development and poverty reduction. In order to achieve this goal the project has identified four key objectives:

- To improve the development and implementation of a transparent and straight-forward policy and regulatory framework for artisanal mining.

- To improve the formation and functioning of institutional structures and organisations within artisanal mining at all levels.

- To strengthen the capacity of artisanal mining communities to engage in profitable and responsible mining and extended business activities aiming to reduce poverty.

- To empower artisanal miners and other resource users to address and solve existing and potential ecological as well as social conflicts responsibly.

To achieve these objectives, a community development team is currently working with ASM communities to develop formal organisational structures which will draft and implement community action plans. To this end, project team members facilitate meetings with community members to help identify community needs and interests and form work groups based on specific needs. ASM communities involved in the project have formed technical, social, and organisational development groups, comprising both men and women miners. 
The project recognises that a multi-faceted approach which addresses social, environmental, legal and economic issues, is ultimately needed to make ASM a more sustainable activity. The project seeks to make ASM more costeffective and therefore more profitable through the introduction of efficient and environmentally friendly tools and technologies. Technology transfer by project staff has included the introduction of chemical free processes for mineral extraction and processing as well as safer tools and technology. This has been coupled with ongoing education and training in safe work practices and occupational health and safety. Another project goal is to promote local economic development through the development of sustainable entrepreneurial entities (SMEs), which will generate formal employment and allow for diversification of labour and products (such as gold washing services, adventure tourism, production of mining equipment or jewelry).

Helping ASM to become an accepted, responsible activity requires dialogue and partnerships with local government authorities. The project is facilitating a process whereby miners will register as citizens, agreeing to pay taxes and entering into contracts to mine specific areas which have a range of clauses that must be adhered to, from upholding occupational safety standards to the rehabilitation of mine sites. In return, miners are able to vote and are offered social and health insurance and access to other government services. The aim of these partnerships is also to help reduce a long history of conflict between small-scale miners, government authorities and large-scale mining operations. At a later stage, it is envisaged that the project will support the formation of civil society organisations at regional and national levels to coordinate artisanal mining activities and represent the ASM community at those levels.

Gender has been mainstreamed throughout project activities in recognition of the participation of women in ASM and the link between the sustainability of ASM and gender roles and relations in ASM communities. All community institutions and structures created by the project must be gender-sensitive, including ASM associations. In terms of gender balance, the proportional participation of women and men in capacity building training, in the implementation of community action plans and in project work with groups of artisanal miners has been mandated. Gender-sensitive training programs and manuals have also been developed to ensure equal access, rights, responsibilities and opportunities for men and women in ASM activities. Gender analysis (the systematic gathering and examination of sex disaggregated data to identify and understand inequities based on gender) has also been a key and ongoing part of the project. 


\section{Conclusion}

Since the transition to a market economy, the mining sector has become a vital part of the Mongolian economy. Although the government has opened large parts of the country up to mineral exploration and extraction by multinational companies, capital-intensive, large-scale mining has boosted GDP, but not generated jobs. As a result, despite a sustained increase in GDP over the last decade, high levels of poverty and unemployment remain. At the same time, ASM has continued to expand and provides a livelihood for an increasing number of Mongolia's rural poor.

If managed in such a way that the social, economic and environmental costs and benefits can be balanced, ASM can contribute to the sustainable development of rural communities. ASM can create financial capital that can be invested in a range of diverse enterprises, build human capital in rural areas by increasing levels of education and technical skills, and generate social capital through redirecting the wealth generated into local economic development, health and welfare.

The World Bank has stated that mining is compatible with sustainable development, able to be achieved through the combination of efficient use of economic capital, maintenance of ecosystem integrity and natural resource productivity with social equity and mobility, participation and empowerment. In order to achieve this model of mining-driven sustainable development, governments need to assist by promoting equitable, participative community development as a basis for economic development. This includes gender equity through gender mainstreaming community development initiatives.

Mongolia's example shows that the regulation and development of ASM can be achieved, but only in partnership with government agencies, large-scale mining companies and other stakeholders. Given the complex web of social, legal and environmental issues involved in ASM, national and local governments and international agencies should assume the lead role in addressing them in partnership with ASM communities. In recognising the historical involvement and high levels of participation of women in small-scale mining in Mongolia, the Sustainable Artisanal Mining Project can also serve as an example of how gender can be integrated into mining-led development initiatives from the outset, in order to achieve a sustainable future for ASM and in so doing, for the many millions of people that depend on ASM for their livelihood. 


\section{References:}

ADB (Asian Development Bank) Mongolia, 2008. 'Country Gender Assessment.' Unpublished report to ADB Mongolia. Ulaanbaatar: ADB Mongolia.

Grayson, R., T. Delgertsoo, W. Murray, B. Tumenbayar, M. Batbayar, U Tuul, D. Bayarbat and C. Erdene-Baatar, (2004). 'The Rise of "Ninja" Phenomenon.' Special Issue 'The People's Gold Rush in Mongolia'. World Placer Journal 4. Viewed 20 January 2011 at: http://www.mine.mn/WPJ4_1_Gold_Rush_in_ Mongolia.pdf

Janzen, J., M. Priester, B. Chinbat and V. Battsengel (eds), 2007. Artisinal and Small-Scale Mining in Mongolia: The Global Perspective and Two Case Studies of Bornuur Sum/Tuv Aimag and Sharyn Gol Sum/Darkhan-Uul Aimag. Research Papers 4. National University of Mongolia: Ulaanbaatar.

MEK Co. Ltd, ILO and IPEC (International Labour Organization and International Program for Elimination of Child Labour), 2005. Baseline survey on child and adult workers in informal gold and fluorspar mining. Population Teaching and Research Center. Beijing: ILO.

MRPAM (Mineral Resources and Petroleum Authority of Mongolia), 2005. Sustainable Artisanal Mining.' Internal project document. Ulaanbaatar: MRPAM

, 2007. 'MRPAM Annual Report.' Artisanal Mining Division Report. Ulaanbaatar: MRPAM.

NDS (National Development Strategy), (2008). 'Millennium Development Goals Based Comprehensive National Development Strategy 2007.' Report from task force to develop comprehensive national development strategy. Ulaanbaatar: Government of Mongolia.

NSOM (National Statistics Office of Mongolia), 2007. 'National Statistical Year Book 2007.' Ulaanbaatar: Government of Mongolia.

SDC (Swiss Agency for Development Cooperation), 2009. 'Sustainable Artisanal Mining Project.' Viewed 20 January 2011 at: http://www.swiss-cooperation. admin.ch/mongolia//ressources/resource_en_184875.pdf

UNFPA (United Nations Population Fund), 2007. 'Socio-Economic Situation of Artisanal Miners in Mongolia.' Ulaanbaatar: UNFPA.

UNDP (United Nations Development Programme) Mongolia, 2008. 'Mongolia Human Development Report 2007.' Unpublished report to the UNDP. Ulaanbaatar: UNDP Mongolia. 